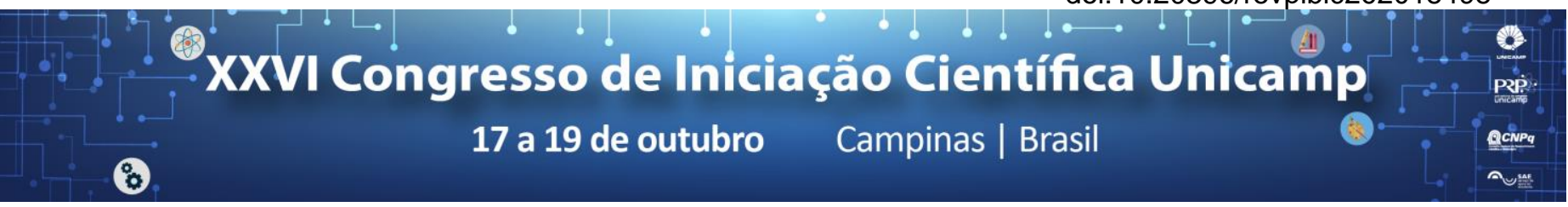

\title{
Avaliação de Amadurecimento de Tomates com a utilização do Biospeckle e sensor Kinect
}

\section{Gabriel Vieira Elmo Ferreira*, Fernanda Fernandes Adimari Pavarin, Fernando de Saes Madeira Vallar, Yu Tzu Wu, Juliana Aparecida Fracarolli.}

\section{Resumo}

O presente projeto tem como objetivo avaliar a maturidade do tomate a partir da utilização do Biospeckle, sensor Microsoft Kinect e Métodos de Laboratório, além de auxiliar o projeto Universal do CNPq processo 424016/2016-8. Foram obtidos dados fisico-químicos das amostras, e as imagens geradas através do sensor kinect em conjunto ao bioscanner forneceram dados de Momento de Inércia (Ml1 e MI2) e AVD (AVD1, AVD2, AVD3 e AVD4), sendo esses, obtidos a partir de análise utilizando softwares matematicos (Octave). Análisando os dados obtidos, foram encontradas diferenciações estatísticas (ANOVA) nos parâmetros estudados de acordo com os estágios de maturidade, e foi elaborada uma correlação com os niveis de amadurecimento do tomate.

Palavras-chave:

Bioscanner, Engenharia Agrícola, Pós-Colheita.

\section{Introdução}

Técnicas ópticas vêm sendo utilizadas para diversas finalidades, caracterizando métodos de análise não invasivos e não destrutivos para diversos campos da engenharia. Dentre as técnicas, o Biospeckle, por meio do cálculo do AVD e MI está sendo utilizado para avaliação de maturidade e teor de água em frutos. Já o sensor Kinect, pode ser utilizado como ferramenta de captura de imagens junto ao laser e ainda produz mapas em 3D de objetos.

Visto que a colheita do tomate (Lycopersicon esculentum Mill) é de extrema importância para que a qualidade esteja na mesa do consumidor, deve-se levar em consideração a ontogênese do mesmo e o momento de maturação durante a colheita. A partir disso, essa pesquisa visa diferenciar estatisticamente propriedades do fruto e correlacionar características de amadurecimento do tomate obtidas por Biospeckle e por métodos tradicionais. Esses dados poderão auxiliar no processo de seleção dos frutos, podendo possivelmente identificar características de maturidade por meio das imagens e dados obtidos.

\section{Resultados e Discussão}

Foi realizada análise físico-química de 5 estágios de maturação diferentes do tomate, com 20 corpos de prova por estágio. Os dados obtidos foram Peso, $\mathrm{pH}$, Brix, Acidez total titulável (ATT), relação BRIX/ATT, Cor e Firmeza. Em conjunto aos testes laboratoriais foram obtidas imagens de biospeckle das 100 amostras, sendo 128 frames a cada rotação de $120^{\circ}$ do fruto, utilizando o Sensor Microsoft Kinect como ferramenta de captura das imagens através de uma interface gráfica de usuário desenvolvida em Visual Studio (Figura 1.a).

A partir da utilização do Software Octave versão 4.2.1, foram obtidos dados de momento de inércia (IM1, IM2) e AVD (AVD1, AVD2, AVD3, AVD4) (BRAGA Jr. et al., 2016) para todas as amostras. Utilizando o software Sisvar (Ferreira, 2014) ANOVA, foi realizado o teste de Tukey em todos os dados, dessa forma foi constatado diferenciações estatísticas esperadas entre os estágios de maturação do tomate (Tabela 1). Observa-se que as médias dos tratamentos para cada maturação possuem diferença estatística. Os tratamentos 1 e 2 não apresentaram essa diferença e foram representados conjuntamente pelo resultado a2. Posteriormente foi obtida a correlação entre os dados obtidos pelo Biospeckle e os dados físico-químicos.
Figura 1. (a) Frame do tomate em 8 bits, biospeckle capturado pelo Sensor Kinect. (b) estados de maturação dos tomates utilizados.

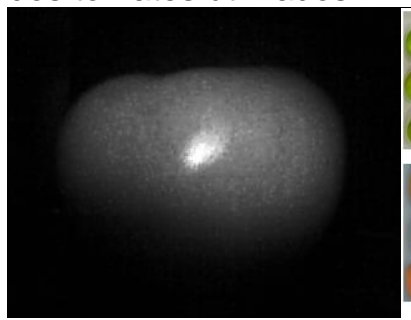

(a)
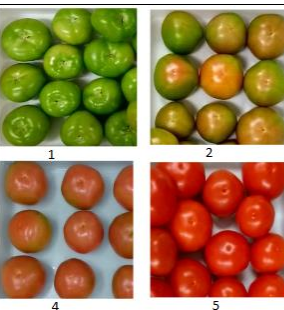

(b)
Tabela 1. Resultado do teste de Tukey para AVD3 e SST para diferentes estágios de maturação.

\begin{tabular}{ccccc}
\hline Tratamento & Média AVD3 & res. Tukey & Média SST & res. Tukey \\
\hline 1 & 6,68 & a2 & 4,26 & a2 \\
2 & 6,34 & a2 & 4,21 & a2 \\
3 & 10,12 & a4 & 3,70 & a1 \\
4 & 3,88 & a1 & 4,75 & a3 \\
5 & 9,40 & a3 & 5,02 & a4 \\
\hline num obs & 300 & & 300 & \\
\hline CV(\%) & 16,72 & & 8,57 \\
\hline
\end{tabular}

*Num obs: Quantidade de amostras observadas; CV: Coeficiente de variação; Tratamento: Estágios de maturação do tomate; res Tukey: Diferenciação estatística das médias, SST: Sólidos Solúveis totais.

\section{Conclusões}

Através desta pesquisa, conclui-se que a diferenciação estatística utilizando o sensor Kinect para os estados de maturação do tomate são eficientes e passíveis de aplicação em processos de pós-colheita, além de iniciar o aprofundamento nas técnicas de correlação de dados físico-químicos aos obtidos a partir do Biospeckle e de dimensionamento dos frutos, anexado ao projeto Universal do CNPq processo 424016/2016-8.

\section{Agradecimentos}

Professora Juliana Fracarolli, CNPq e ao PIBIC pela bolsa.

FERREIRA, Daniel Furtado. Sisvar: a Guide for its Bootstrap procedures in multiple comparisons. Ciênc. agrotec. [online]. 2014, vol.38, n.2 [citado 2015-10-17], pp. 109-112.

BRAGA JÚNIOR, R. A.; RIVERA, F. P.; MOREIRA, J. A practical guide to biospeckle laser analysis: theory and software. Lavras: Ed. UFLA, 2016. 